\title{
A CRISE DO ESTADO SOCIAL NA EUROPA OCIDENTAL E NA AMÉRICA LATINA CONTEMPORÂNEA E A PRECARIZAÇÃO DOS DIREITOS FUNDAMENTAIS SOCIAIS: UM ESTUDO A PARTIR DAS REFERÊNCIAS BRASILEIRAS E PORTUGUESAS
}

ROCHA, Manoel Ilson Cordeiro ${ }^{1}$

ISSUE DOI: $10.3738 / 1982.2278 .1468$

\begin{abstract}
RESUMO: Este estudo aponta efeitos da crise contemporânea do Estado Social, em especial na Europa Ocidental e nas democracias latino-americanas (no que é possível generalizar a partir das referências portuguesa e brasileira), especialmente sobre a efetivação dos direitos fundamentais sociais, sob a perspectiva de um Estado Democrático e de Direito, que reconhece os direitos sociais como necessários para a emancipação do indivíduo e para a consolidação da democracia. O Estado Social enfrentou e enfrenta até hoje uma crise de gerenciamento e, simultaneamente, de contradição com uma economia global e de severa competitividade. Os resultados encontrados mostram que, em consequência do neoliberalismo, ocorreram reformas constitucionais restritivas e restrições orçamentárias recentes para investimentos sociais, principalmente após a queda do muro de Berlim e a internacionalização da economia por medidas nacionais de liberação das fronteiras alfandegárias. A ordem neoliberal resultou perversa quanto aos interesses democráticos e populares. Quanto aos direitos sociais comprometidos com o neoliberalismo, o desafio é saber até que ponto os limites aos direitos não significam um comprometimento da ordem constitucional e como o ordenamento preencherá a lacuna dos limites aos limites.
\end{abstract}

Palavras-Chave: Estado social. Direitos fundamentais. Neoliberalismo.

SUMMARY: This study explores the effects of the crisis of the Social State of the social rights, but under the perspective of a Democratic State and of Right, which recognizes the social rights like necessary for the emancipation of the individual and for the consolidation of the democracy. The considered results show that, as a consequence of the neoliberalism, constitutional restrictive reforms and budgetary restrictions took place for social investments. The neoliberalism turned out to be perverse as for the democratic and popular interests. It the question is a bibliographical and critical study of the neoliberalism.

Keywords: Social State. Basic rights. Neoliberalism.

\section{INTRODUÇÃO}

A crise contemporânea do Estado Social afetou principalmente a efetivação dos direitos sociais constitucionalizados no século XX, sob o discurso da restrição de recursos e da má gestão pública. O póssegunda guerra foi frutífero na expansão e constitucionalização de direitos fundamentais, primeiro porque ampliou o leque de tais direitos e segundo porque lhe atribuiu uma condição fundamental e de prérequisito do Estado, adotada especialmente nas democracias da Europa Ocidental e, gradativamente, nas democracias da América Latina. Mas o discurso neoliberal hegemônico das últimas três décadas produziu reformas restritivas de direitos, em conflito com os interesses protegidos nas Constituições. A abertura comercial internacional que ocorreu globalmente, com sua imanente concorrência agressiva, tem continuamente erodido os recursos públicos que naturalmente financiam as políticas sociais.

Mas até que ponto a renúncia aos direitos sociais não significa uma renúncia à democracia e ao Estado de Direito? E até que ponto é possível retroceder diante da legitimidade de tais direitos no imaginário popular e na solidez das instituições democráticas? A antinomia entre os pilares da revolução liberal de liberdade e igualdade se renova com o déficit produzido pelo Estado neoliberal, e a promessa da revolução - de emancipação do indivíduo - é novamente adiada. 
Consequente deste debate se encontra a questão dos limites aos direitos fundamentais, em especial os sociais, enquanto prerrogativa do Estado para definir quais são os direitos realmente devidos e como efetivá-los ou enquanto conjunto de direitos constitucionalmente garantidos e inerentes ao pacto social vigente. A natureza dos limites aos direitos fundamentais, em especial os sociais, mais do que uma questão de teoria do direito e modo de interpretação de um direito fundamental, é uma questão do fundamento ideológico do Estado.

\section{CRISE DO ESTADO SOCIAL E PRECARIZAÇÃO DOS DIREITOS FUNDAMENTAIS SOCIAIS}

\subsection{O contexto de crise do estado social}

Entende-se por Estado Social a ordem político-jurídica moderna fundada na proteção social e na segurança econômica garantida pela intervenção do Estado nos limites da democracia e do Estado de Direito. Juridicamente se manifesta pela constitucionalização de direitos de natureza social ${ }^{2}$, de responsabilidade do Estado, garantidos efetivamente pela forte intervenção estatal na economia. A presença do Estado na economia, que foi o grande debate do século XX, evoluiu para um capitalismo de Estado forte, fundado no Keynesianismo.

O modelo de Estado Social foi também uma resposta à polarização entre liberalismo e socialismo, por isso mesmo não significou apenas um modelo de gestão pública, mas de uma verdadeira configuração ideológica. Esta caracterização é, naturalmente, expressa no domínio constitucional, onde os princípios se formaram num conjunto coerente e coeso com o modelo. Sua expansão ocorreu principalmente após a segunda guerra mundial nos países europeus continentais, mas contemplou um universo maior, que é relativamente representada ainda hoje pela OCDE (Organização para Cooperação e Desenvolvimento Econômico). Na América Latina a maioria dos Estados adotaram Constituições de ampla proteção social, mas há um descompasso entre os direitos constitucionalizados e os direitos efetivados. As políticas sociais da região vieram tardiamente e limitadas por conta das próprias limitações de suas economias, assim como a expansão foi frustrada pela pauta neoliberal.

Mas, no geral, o Estado Social teve vigorosos êxitos no pós-guerra e por três décadas parecia a melhor opção de regulação social. Entretanto, em meados dos anos setenta as socialdemocracias entraram num ciclo de inflação, desemprego crescente e déficit de produtividade, com a conseqüente elevação dos custos da proteção do desemprego, com a erosão do poder aquisitivo pela inflação e a elevação constante dos custos dos demais serviços sociais e de burocracia pública. $\mathrm{O}$ que foi prontamente associado à incapacidade do Estado de financiar a proteção social e de participar da gestão da economia. As políticas públicas para garantir o pleno emprego por via de investimentos na economia e refinanciamento do ciclo produtivo mostrou um Estado mau gestor, principalmente porque não atuava sobre a lógica da competitividade. Por outro lado, o ciclo crescente de benefícios públicos, fundado em valores éticos emancipadores do indivíduo em sociedade, com mais serviços e garantias, não foi companhado pelo respectivo crescimento de receita ${ }^{3}$. O Estado Social se deparou com a crítica neoliberal de que ele é

\footnotetext{
${ }^{2}$ Calcado no discurso humanista do século XX, expresso nas Constituições garantistas de direitos fundamentais de segunda geração.

${ }^{3}$ Para Jorge Miranda, a crise do Estado social é "derivada não tanto de causas ideológicas (o refluxo das idéias socialistas ou socializantes perante idéias neoliberais) quanto de causas financeiras (os insuportáveis custos de serviços cada vez mais extensos para populações activas cada vez menos vastas), de causas administrativas (o peso da burocracia, não raro acompanhada de corrupção) e de causas comerciais (a quebra da competitividade, numa economia globalizante, com países sem o mesmo grau de protecção social)” MIRANDA, Jorge. Manual de Direito Constitucional, Tomo I. Coimbra: Coimbra; 1996, p. 98.
}

Nucleus,v.13,n.1,abr.2016 
conceitualmente inviável.

De fato, o Estado Social acreditou demasiadamente na fórmula Keynesiana de que a resposta do investimento público na economia seria suficiente para suportar o crescimento das demandas sociais. Não considerou devidamente o crescimento da burocracia, as vicissitudes da riqueza privada e a demasia das demandas sociais com o crescimento e envelhecimento da população. Por fim, o sistema político funcionou sob a lógica eleitoral e momentânea, sem um planejamento estável e de longo prazo.

As crises do petróleo da década de 70 impulsionaram a derrocada do Estado Social. Primeiro porque comprometeram os orçamentos públicos com a elevação dos custos da principal fonte energética, acelerando o endividamento dos Estados e os subjugando às avaliações de decisões do sistema financeiro internacional. Segundo porque forçou uma corrida por tecnologias alternativas e por sistemas operacionais de produção pós-fordistas que reduzissem custos e garantissem competitividade. Estes novos modelos, entre eles as flexibilizações legais das relações de trabalho, a abertura dos mercados e o toyotismo, vieram acompanhados de exigências de gestões públicas também mais dinâmicas, flexíveis e principalmente eficientes e de baixo custo.

Sob a perspectiva da globalização dos mercados, uma nova ordem social se moldou gradativamente, com reflexos contundentes nos sistemas políticos e jurídicos. O modelo anterior, de maior consistência da soberania, de legitimidade fundada em políticas públicas de garantias e de crescimento econômico estatista, foi substituído pela abertura de mercados, crise do Estado Social e investidor e emergência de novos atores nas relações de poder, oriundos da sociedade globalizada.

Mas apesar das reformas neoliberais, o cenário atual ainda é de uma máquina pública agigantada e de custo elevado. Isto porque os governos neoliberais se depararam com uma máquina burocrática irrefreável, assim como constataram que as reformas esbarram num limite perigoso: atingir um patamar muito maior de cortes de serviços públicos pode desencadear um ambiente de convulsão social. Por outro lado, se as medidas tomadas até então foram necessárias, como continuar o processo de reforma do Estado?

Este problema é ainda emergente, porque os Estados estão, de regra, no limite suportável de suas cargas tributárias e já cortaram o que aparentemente seria possível cortar. Entretanto, a adoção pública de técnicas privadas de gestão passa a ser uma importante alternativa à solvência do Estado, e isto já se verifica com a defesa e emprego de princípios que lhes são típicos, como o princípio da eficiência.

\subsection{A desregulação e a precarização dos direitos sociais}

Este ambiente de crise produziu e ainda produz a desregulação e a precarização dos direitos sociais, sob o eco do discurso de reforma do Estado. Aos poucos são introduzidas reformas constitucionais que afetam a proteção dos direitos sociais. Por exemplo, no Brasil sucessivas emendas constitucionais promoveram reformas no sistema previdenciário, na presença do Estado na economia, no controle do orçamento público, sempre no sentido de reduzir o Estado e a sua capacidade de intervenção. Em Portugal a revisão constitucional de 89, ao mudar o caráter interventivo do Estado, no fundo fragilizou a proteção aos direitos fundamentais sociais. Não necessariamente todas as medidas denominadas neoliberais significaram uma afetação à proteção dos direitos fundamentais sociais, mas é possível fazer uma generalização do fenômeno sob o argumento de que, em conjunto, as reformas pertencem a uma orientação ideológica restritiva de tais direitos.

Sob a ótica dos efeitos do Estado neoliberal no debate jurídico, há duas perspectivas: a defesa dos direitos sociais, com fundamento na orientação constitucional, ou a adesão ao discurso reformista com 
uma gradual precarização da prestação dos serviços. O problema se agrava porque, se de um lado as conquistas do Estado Social são por si só legítimas, não se pode ignorar os fundamentos da crise do Estado, com o seguinte questionamento: a insistência em preservar um Estado juridicamente social sob a égide de um Estado politicamente neoliberal é uma inconsequência ou uma resistência? Por que de duas uma, ou alimentará um desequilíbrio entre os que estão protegidos por força da lei e os que não estão, ou se instaurará uma farsa de um sistema jurídico alienado da realidade e sustentado puramente na sua retórica. Assim como não podemos negar o papel e o direito da sociedade civil de resistir às opções do Estado.

É preciso que a resposta jurídica à crise do Estado Social considere a importância do seu legado, assim como também os fundamentos que levaram à crise são intimamente ligados à efetivação dos direitos sociais. Trata-se de uma promessa política e juridicamente irrealizável, resumido num brocardo jurídico: ad impossibilita nemo tenetur (ninguém é obrigado a coisas impossíveis)?

\section{A PRERROGATIVA DOS DIREITOS FUNDAMENTAIS SOCIAIS NO ESTADO DEMOCRÁTICO E DE DIREITO}

\subsection{A natureza e o status dos direitos fundamentais sociais no estado democrático e de direito.}

Os direitos fundamentais foram identificados e garantidos em gerações que, em essência, se contrapõem. O conjunto das liberdades individuais de primeira geração impõe ao Estado obrigações negativas, no sentido de se abster de seu caráter interventivo em prol da efetivação destes direitos. Politicamente significou uma conquista do pensamento e da ideologia liberal clássica, de motivação econômica burguesa. De outro modo, o conjunto de direitos sociais de segunda geração impõe ao Estado obrigações positivas, que dependem do seu caráter interventivo em prol da efetivação destes direitos. Politicamente, seja atendendo à agenda ideológica socialista ou à agenda social-democrata, esta segunda geração implicou em conquistas sociais contrárias ao ideal liberal de Estado ${ }^{4}$.

O artigo 18, número 1 da atual Constituição da República de Portugal vincula expressamente todos os poderes do Estado aos direitos fundamentais. Também a Constituição Federal do Brasil (1988) reconhece a prerrogativa dos direitos fundamentais. A ideia de Constituição democrática é indissociável do projeto moderno de emancipação do indivíduo, entendido como a antítese à medievalidade, ao propor a ruptura com a sociedade estamental pela promoção de liberdades fundamentais e da igualdade.

Incapaz de resolver plenamente a contradição entre liberdade e igualdade, o Estado liberal conferiu um sentido esvaziado de igualdade, caracterizado pelo formalismo e pela estrita configuração de igualdade perante a lei. Mas como promessa da modernidade de emancipação do indivíduo, a igualdade ganhou evidência no século XX e renovou a antinomia com as liberdades fundamentais. O problema dos Estados liberais e dos socialistas sempre foi a necessidade de resolver esta antinomia, seja para um lado ou para o outro, a social-democracia procurou a compatibilização e mesmo após a sua crise, no Estado neoliberal, esta perspectiva não foi superada.

\footnotetext{
${ }^{4}$ Esta distinção não pode ser ignorada - ainda que a dicotomia entre capitalismo e socialismo tenha se esvaziado ou mesmo ainda que a social democracia esteja em crise -, porque este rol de direitos permanece e são legitimamente reivindicados em sociedade. Preferimos a expressão "limites", no sentido de identificar não somente o ponto máximo de um direito, mas também de delimitar a abrangência deste direito. Jorge Miranda diferencia restrição de limite, "a restrição tem que ver com o direito em si, com a sua extensão objetiva; o limite ao exercício de direitos contende com a sua manifestação, com o modo de se exteriorizar através da prática do seu titular" (MIRANDA, Jorge. Manual de Direito Constitucional. Tomo IV: direitos fundamentais. Coimbra: Coimbra Editora, 2008, p. 311).
} 
As exigências de igualdade material só podem ser assumidas enquanto exigências constitucionais porque do princípio constitucional da socialidade decorre uma necessária superação da compreensão da igualdade como mera igualdade formal perante a lei geral e abstrata (NOVAIS, p. 298).

A igualdade material produzida pela intervenção do Estado em sociedades democráticas, sob uma concepção social democrata, tem gradativamente perdido espaço em reformas restritivas denominadas neoliberais. Por outro lado, a história nos ensinou que o livre mercado é incapaz de promover justiça social.

\subsection{Limites $x$ prerrogativa dos direitos fundamentais}

A doutrina e a jurisprudência se estendem longamente no debate sobre os limites versus a prerrogativa dos direitos fundamentais. Seja para interpretar o real sentido dos limites constitucionais expressos, seja para identificar limites imanentes. Segundo Emerson Garcia,

Identifica-se uma espécie de 'conflito permanente' entre o indivíduo e o Estado guardião da ordem pública, onde o primeiro tende a abusar dos direitos de que dispõe e o segundo, por seus agentes, tende a acreditar que sua missão é mais importante que os obstáculos que encontra. Essa relação entre indivíduo e Estado pode ser vista como a 'relação entre duas esferas em iteração', com momentos de compressão e de expansão de cada uma delas (GARCIA, p. 287).

Até a expressão "limite" é, por vezes, substituída por "restrição"

Há os limites estabelecidos pelo legislador, numa ampla extensão, desde os limites constitucionais até aqueles autorizados pela Constituição e dentre estes, desde uma pena restritiva de liberdade até uma limitação ao uso da propriedade, e há também limites intrínsecos aos direitos fundamentais que, mesmo quando não sejam legalmente definidos, são válidos, pois imanam de uma ordem democrática e de um Estado de Direito ${ }^{6}$. Canotilho enumera a seguinte tipologia de restrições:

Limites constitucionais directos ou imediatos $=$ limites directamente estabelecidos pela própria constituição; 2. Limites estabelecidos por lei, mediante autorização expressa da constituição (reserva de lei restritiva ); 3. Limites imanentes ou implícitos (= limites constitucionais não escritos, cuja existência é postulada pela necessidade de resolução de conflitos de direitos e bens) (CANOTILHO, p. 615/616).

Mas, desde já, constata-se que a margem de limitação aos direitos fundamentais é demasiadamente larga, o suficiente para significar um risco aos próprios direitos, e a natureza de tais direitos é também demasiadamente complexo para uma definição que permita uma limitação imanente. De forma que há problemas tanto em discutir a extensão e a natureza das limitações para garantir a preservação dos direitos, quanto o seu contrário, que é o debate sobre a natureza de direitos enquanto objeto jurídico limitado.

Neste sentido se encontram os limites aos limites de direitos fundamentais, como na Constituição Portuguesa. Como se trata de barreiras que afetam a essência do Estado de Direito e da democracia, principalmente pela ação tendencialmente constrangedora do Estado, em Portugal estes limites aos limites

\footnotetext{
${ }^{5}$ Por exemplo, como decorrência dos princípios-direitos da igualdade e da legalidade, são, respectivamente, limites, o respeito a igual direito de outrem e a manutenção da ordem pública.

6 NOVAIS, Jorge Reis. As restrições aos direitos fundamentais não expressamente autorizadas pela Constituição (tese de doutoramento). Lisboa: Faculdade de Direito de Lisboa, 2002, p. 162.
}

Nucleus,v.13,n.1,abr.2016 
foram discriminados em texto constitucional, no artigo 18, número 2 e 3. São os seguintes, na Constituição da República Portuguesa: a) reserva legal constitucional; b) respeito ao igual direito de outrem; c) caráter geral e abstrato; d) irretroatividade; e) manutenção da extensão e do alcance do conteúdo essencial dos direitos; f) proporcionalidade. Entretanto, a regulação objetiva dos limites aos limites tem se mostrado insuficiente, principalmente diante da inevitabilidade de limites que dependem de caso a caso, na ocorrência múltipla de possibilidades de conflitos, evocando esta categoria de limites imanentes ou implícitos.

A doutrina, então, se esforça no sentido de identificar a natureza das limitações e dos direitos. Assim, cabem ao legislador, mais do que limitar o direito, também regulá-lo e esclarecê-lo, o que implica numa atividade legislativa ampla e com margem a outro problema: até que ponto a regulação e o clareamento do direito fundamental não significam uma ação restritiva do direito? O artigo 18 fala em "restringir", então é preciso identificar o que diferencia e o que aproxima restrição de regulação. O fim da regulação e clareamento é conferir objetividade ao direito de forma a contribuir para a sua efetivação. É possível, entretanto, que uma regulação implique simultaneamente numa restrição, mas não necessariamente. A norma reguladora pode dizer quais os procedimentos para a garantia de um direito, como pode também dizer quais são exatamente estes direitos, regulamentando-os, mas também excluindo outras hipóteses.

Novais aponta a dificuldade de distinguir regulação de restrição. Segundo o autor, a regulação em si implica uma finalidade restritiva, ainda que existam normas que intervêm no conteúdo de um direito para o seu desenvolvimento. Estas normas não poderiam ser interpretadas além deste fim e não poderiam significar restrições, para que não sejam submetidas aos limites dos limites. Em Portugal, a regulação deve se sujeitar aos limites de limites expressos no artigo 18 da Constituição, quando implicar indiretamente numa restrição de direitos ${ }^{7}$. Para Novais os requisitos do artigo 18, que são corolários do Estado de Direito, são aplicáveis a qualquer norma, desde que implique em afetar restritivamente os direitos fundamentais, mesmo que não sejam normas explicitamente restritivas. Porém, não se aplica quando a norma tenha caráter pacificamente reconhecido de ausência de qualquer efeito restritivo.

$\mathrm{Na}$ Constituição brasileira não houve uma preocupação em estabelecer limites aos limites. Eles ocorrerão pela interpretação constitucional segundo a sua hierarquia de normas.

\section{RESULTADO E CONCLUSÃO}

O debate proposto conflita a efetivação dos direitos fundamentais sociais com os tempos de crise do Estado Social (especificamente no âmbito das democracias ocidentais europeias e latino-americanas atuais). Esta é apresentada como uma limitação a tais direitos.

\footnotetext{
${ }^{7}$ Novais mostra que em Portugal o Tribunal Constitucional adota uma orientação inconstante. Para os casos fáceis, adere a uma concepção clássica de restrição, segundo a "teoria externa", onde a regulação fica sujeita aos limites a limites. E nos casos difíceis, seguindo a "teoria interna", permite ao legislador regulamentar, onde não há caracterização expressa de restrição, conforme uma função de densificação, sem os mesmos limites, e distinguindo regulamentação de restrição, recorrendo à proporcionalidade ou razoabilidade para distinguir esta fronteira. Segundo o autor, "o critério decisivo é, sobretudo, o teste da proporcionalidade da medida: aquilo que na realidade distingue não é o serem restrições e, em alternativa, meros condicionamentos do direito fundamental, mas sim constituírem, respectivamente, medidas restritivas desproporcionadas ou medidas razoáveis e constitucionalmente justificadas. No entanto, formalmente, a fundamentação da decisão é sempre apresentada como se baseando numa pretensa distinção primária entre restrição e regulamentação/condicionamento". Este critério torna inócuo ou sem relevância os limites aos limites, pois o Tribunal, distinguindo as restrições conforme a proporcionalidade diante de outra figura, recorre ao artigo 18 quando configura a desproporção, ou seja, quando já não é necessário. (NOVAIS, Jorge Reis. As restrições aos direitos fundamentais não expressamente autorizadas pela Constituição (tese de doutoramento). Lisboa: Faculdade de Direito de Lisboa, 2002, p. 169/170).
} 
O Estado Social produziu proteção social fundado na sua constitucionalização e na segurança econômica garantida pela intervenção do Estado. Mas a sua crise é atribuída a uma dificuldade de gestão dos recursos públicos suficientes ao seu projeto social. $\mathrm{O}$ neoliberalismo acusa este projeto de inviabilidade, o que é rebatido apontando este discurso como uma retórica em prol de um mercado global, perverso e desregulado.

Porém, inúmeras reformas desreguladoras e desprotetivas foram implementadas, e sem sucesso. O ambiente ainda é de crise. Por outro lado, a desregulação esbarra na garantia dos direitos sociais constitucionalizados. Trava-se um debate dos seguintes contornos: a defesa dos direitos sociais, com fundamento na orientação constitucional, ou a adesão ao discurso reformista de busca do equilíbrio orçamentário com uma gradual precarização da prestação dos serviços. A grande questão é saber quais são os limites aos direitos sociais e quem é competente para identificá-los. A ordem jurídica portuguesa impõe, em sede constitucional, limites aos limites de direitos, mas não se alcançou uma solução definitiva.

Cabem ao legislador, mais do que limitar o direito, também regulá-lo e esclarecê-lo, o que implica numa atividade legislativa ampla e com margem a outro problema: até que ponto a regulação e o clareamento do direito fundamental não significam uma ação restritiva do direito. É importante que o legislador não confunda regulação com restrição.

Este debate pode ser ampliado com a identificação da natureza da norma constitucional material, confrontando a atividade normativa do administrador e do legislador ordinário com os princípios estabelecidos na Constituição.

\section{REFERÊNCIAS}

ALEXY, R.. Teoria dos direitos fundamentais. 2. ed. São Paulo: Malheiros, 2008.

ANDRADE, J.C.V.de. Os direitos fundamentais na Constituição portuguesa de 1976. Coimbra: Almedina, 1983.

BARROSO, L.R.. Temas de Direito Constitucional. Vol. I. Rio de Janeiro/São Paulo: Renovar, 2001.

BOLZAN DE MORAIS, J.L.. O Estado e seus limites, reflexões iniciais sobre a profanação do Estado Social e a dessacralização da modernidade. IN: OLIVEIRA NETO, F.J.et al. (org.). Constituição e Estado Social: os obstáculos à concretização da Constituição. Coimbra: Coimbra, 2008.

BONAVIDES, P.. Curso de Direito Constitucional. São Paulo: Malheiros, 2007.

CANOTILHO, J.J.G.. Metodologia 'fuzzy' e 'camaleões normativos' na problemática atual dos direitos econômicos, sociais e culturais. In: CANOTILHO, J.J.G.. coord.). Estudos sobre direitos fundamentais. Coimbra: Coimbra, 2004.

CANOTILHO, J.J.G.. Direito Constitucional. Coimbra: Almedina, 1992.

CANOTILHO, J.J. GOMES; STRECK, L.. Entre discursos e culturas jurídicas. Coimbra: Coimbra, 2006.

DWORKIN, R.. Levando os direitos a sério. São Paulo: Martins Fontes, 2002.

ESTORNINHO, M.J.. A fuga para o direito privado. Coimbra: Almedina, 1996.

FARIA, J.E.et al. Direito e Globalização Econômica: implicações e perspectivas. São Paulo: Malheiros, 2010. 
GARCIA, E.. Conflito entre normas constitucionais: esboço para uma teoria geral. Rio de Janeiro: Lumen Juris. 2008.

MELLO, C.A.B.de. Curso de direito administrativo. São Paulo: Malheiros, 2003.

MIRANDA, J.. Manual de Direito Constitucional. Tomos II, IV e VI: Coimbra: Coimbra, 2008.

NOVAIS, J.R.. As restrições aos direitos fundamentais não expressamente autorizadas pela

Constituição (tese de doutoramento). Lisboa: Faculdade de Direito de Lisboa, 2002.

NOVAIS, J.R.. Os princípios constitucionais estruturantes da república portuguesa. Coimbra: Coimbra, 2004.

OLIVEIRA NETO, F. J. R. et al. (org.). Constituição e Estado Social: os obstáculos à concretização da Constituição. Coimbra: Coimbra, 2008.

PIOVESAN, F.. Direitos Humanos e o Direito Constitucional Internacional. São Paulo: Saraiva, 2007.

ROCHA, M.I. C.. Reflexão sobre o conceito de soberania frente à desterritorialização provocada pela globalização econômica. Dissertação (Mestrado). Franca: UNESP, 2000.

ROSANVALlON, P.. A crise do Estado-providência. Brasília: Ed. da UNB; Goiânia: Ed. da UFG, 1997.

SARLET, I.W.; TIMM, L. B.. (org.) Direitos fundamentais: orçamento e reserva do possível. Porto Alegre: Livraria do Advogado, 2008.

STREK, L.L.. Constituição e hermenêutica em países periféricos. In: OLIVEIRA NETO, Francisco José Rodrigues e outros (org.). Constituição e Estado Social: os obstáculos à concretização da Constituição. Coimbra: Coimbra, 2008.

SOARES, G.. Restrições aos direitos fundamentais: a ponderação é indispensável? In: MIRANDA, Jorge (coord.). Estudos em homenagem ao Professor Doutor Joaquim Moreira da Silva Cunha. Lisboa: FDUL, 2005. 